\title{
Clip ligation of contralateral P1 aneurysm: extending the working depth of microsurgery along the skull base
}

\author{
Karishma Vijay Rupani and Aaron A. Cohen-Gadol, M.D., M.Sc. \\ Goodman Campbell Brain and Spine, Indiana University Department of Neurological Surgery, Indianapolis, Indiana \\ Clip ligation of posterior circulation aneurysms can be challenging because of limited operative working space and \\ angles. Certain proximal posterior cerebral (P1) aneurysms are especially challenging because of their locations within \\ the lateral anterior interpeduncular fossa. \\ We present a 52-year-old woman who had previously undergone coil embolization of a ruptured right-sided posterior \\ communicating artery aneurysm. She also had two other small aneurysms (left posterior communicating artery and \\ right $\mathrm{P} 1$ aneurysms). She underwent clip ligation of the latter two unruptured aneurysms through a left-sided pterional \\ craniotomy. The microsurgical techniques to clip ligate a contralateral P1 aneurysm are discussed in the video.
}

The video can be found here: http://youtu.be/YBE7FcFGlpQ.

KEY WORDS microsurgical clip ligation; contralateral aneurysm; P1 aneurysm 